\title{
Suboptimal maternal nutrition, during early fetal liver development, promotes lipid accumulation in the liver of obese offspring
}

\author{
M A Hyatt ${ }^{1}$, D S Gardner ${ }^{3}$, S Sebert ${ }^{2}$, V Wilson ${ }^{1}$, N Davidson ${ }^{1}$, Y Nigmatullina ${ }^{1}$, L L Y Chan ${ }^{1}$, \\ $\mathrm{H}$ Budge $^{2}$ and M E Symonds ${ }^{2}$ \\ ${ }^{1}$ Early Life Nutrition Research Unit, Academic Child Health and ${ }^{2}$ Respiratory Biomedical Research Unit, School of \\ Clinical Sciences, Queen's Medical Centre, University Hospital, Nottingham NG7 2UH, UK and ${ }^{3}$ School of \\ Veterinary Medicine and Science, University of Nottingham, Nottingham LE12 5RD, UK
}

Correspondence should be addressed to M E Symonds; Email: michael.symonds@nottingham.ac.uk

M A Hyatt is now at School of Medicine, Centre for Health Information, Research and Evaluation, Swansea University, Singleton Park, Swansea SA2 8PP, UK

\begin{abstract}
Maternal nutrition during the period of early organ development can modulate the offspring's ability to metabolise excess fat as young adults when exposed to an obesogenic environment. This study examined the hypothesis that exposing offspring to nutrient restriction coincident with early hepatogenesis would result in endocrine and metabolic adaptations that subsequently lead to increased ectopic lipid accumulation within the liver. Pregnant sheep were fed either 50 or $100 \%$ of total metabolisable energy requirements from 30 to 80 days gestation and $100 \%$ thereafter. At weaning, offspring were made obese, and at $\sim 1$ year of age livers were sampled. Lipid infiltration and molecular indices of gluconeogenesis, lipid metabolism and mitochondrial function were measured. Although hepatic triglyceride accumulation was not affected by obesity per se, it was nearly doubled in obese offspring born to nutrient-restricted mothers. This adaptation was accompanied by elevated gene expression for peroxisome proliferator-activated receptor $\gamma$ (PPARG) and its co-activator PGC1 $\alpha$, which may be indicative of changes in the rate of hepatic fatty acid oxidation. In contrast, maternal diet had no influence on the stimulatory effect of obesity on gene expression for a range of proteins involved in glucose metabolism and energy balance including glucokinase, glucocorticoid receptors and uncoupling protein 2. Similarly, although gene expressions for the insulin and IGF1 receptors were suppressed by obesity they were not influenced by the prenatal nutritional environment. In conclusion, excess hepatic lipid accumulation with juvenile obesity is promoted by suboptimal nutrition coincident with early development of the fetal liver. Reproduction (2011) 141 119-126
\end{abstract}

\section{Introduction}

Chronic excess energy intake combined with sedentary behaviour results in obesity, hyperlipidaemia and insulin resistance (Bellisari 2008). These adaptations are associated with the development of the metabolic syndrome and non-alcoholic fatty liver disease (NAFLD; Dixon et al. 2001), conditions now occurring in substantial numbers of children and adults (Moscatiello et al. 2007, Lidofsky 2008). We have recently established an ovine model for the metabolic syndrome, which demonstrates differential adaptations following exposure to a post-weaning obesogenic environment that is dependent on the animal's prenatal nutritional environment (Williams et al. 2007, Sebert et al. 2009). This is important because in fast developing countries, such as
India and China, the adoption of a more western lifestyle has resulted in generations of children and young adults, many previously undernourished in utero, being exposed to an environment of plenty, potentially predisposing them to the early development of obesity and its complications.

Irrespective of the in utero environment, young adult obese sheep exhibit raised fasting plasma nonesterified fatty acid (NEFA), leptin and insulin (Williams et al. 2007, Sebert et al. 2009), together with molecular markers of inflammation in the kidney and adipose tissue (Sharkey et al. 2009a, 2009c). However, obese offspring born to nutrient-restricted mothers demonstrate greater insulin resistance as indicated by raised insulin (Sebert et al. 2009), enhanced ectopic lipid accumulation in 
the heart (Chan et al. 2009) and impaired function of the endoplasmic reticulum in adipose tissue (Sharkey et al. $2009 b$ ). These findings raise the question as to whether in utero nutritional programming followed by exposure to an obesogenic environment fits with a 'two hit' hypothesis for the pathogenesis of NAFLD (Day 2002). The first challenge would cause insulin resistance and chronic inflammation (Xu et al. 2003), while the second, following exposure to an obesogenic environment, would result in hepatic steatosis (Brunt 2007), fibrosis and abnormal mitochondrial $\beta$ oxidation (Tessari et al. 2009). We therefore hypothesised that ectopic lipid accumulation would be amplified with obesity in offspring born to nutrient-restricted mothers as hepatic endocrine sensitivity to both glucocorticoids and insulinlike growth factors (IGF) is reset during development in these animals (Hyatt et al. 2007).

To date, numerous small animal models dependent on the presence of a genetic defect and/or the consumption of more extreme diets either in adulthood (Weltman et al. 1996, Enriquez et al. 1999, Lieber et al. 2004, Ayala et al. 2009, Fu et al. 2009, Li et al. 2009) or in early life (Bruce et al. 2009) have been adopted to study NAFLD. They have shown that peroxisome proliferatoractivated receptor $\alpha$ (PPARA), a regulator of a number of mitochondrial fatty acid metabolising enzymes in the liver, underpins the development of NAFLD. We, therefore, examined some of these primary regulators of hepatic energy metabolism in order to determine whether these are differentially affected by obesity and in utero exposure to maternal nutrient restriction. Ultimately, we aimed to establish a developmental model of NAFLD based on a large mammal and mediated by changes in dietary intake, rather than composition, through pregnancy. Studies in NAFLD are particularly confusing due to the multiple potential sources of excess triglyceride (TAG), i.e. de novo synthesis, uptake of NEFA released from adipose tissue lipolysis, uptake of dietary TAG, reduced hepatic fatty acid oxidation and reduced release of TAG in the form of very low-density lipoproteins. In a recent study (Fabbrini et al. 2008, 2009), NAFLD was associated with changes in all of these indices. Sheep therefore represent a particularly interesting model for examining lipid trafficking between tissues because de novo synthesis of NEFA is restricted to adipose tissue, which is the only source of long-chain TAG (Ingle et al. 1972).

\section{Results}

\section{Body composition, liver weight and metabolic profile}

Complete body composition and metabolic profiles at 1 year of age for all lean $(\mathrm{L})$, obese $(\mathrm{O})$ and obese offspring born to nutrient-restricted mothers (NRO) have been described previously (Williams et al. 2007, Sebert et al. 2009) but data essential for the full interpretation of the new data obtained from the liver are included in this study. Obesity resulted in an increased total fat mass irrespective of the prenatal nutritional environment (i.e. L: $2.5 \pm 0.3$; O: $8.0 \pm 0.3$; NRO: $7.7 \pm 0.6 \mathrm{~g} / \mathrm{kg}(P<0.001))$ and had no effect on relative liver weight (i.e. L: $10.3 \pm 0.3$; O: $9.9 \pm 0.6$; NRO: $10.1 \pm 0.6 \mathrm{~g} / \mathrm{kg}$ ). Obesity was accompanied by raised fasting plasma NEFA, leptin and insulin concentrations, with the insulin response being enhanced in the NRO animals (insulin - L: $0.6 \pm 0.1 ;$ O: $1.0 \pm 0.3$; NRO: $1.6 \pm 0.3 \mathrm{ng} / \mathrm{ml}(P<0.05))$ but all animals remained normoglycaemic (glucose - L: $4.6 \pm 0.3 ; \mathrm{O}: 5.9 \pm 0.7$; NRO: $5.3 \pm 0.7 \mathrm{mmol} / \mathrm{l})$.

\section{Hepatic TAG concentration and histological analysis}

Although juvenile-onset obesity alone had no effect on hepatic TAG content, this was significantly raised in obese offspring born to nutrient-restricted mothers (Fig. 1a). Hepatic lipid content, determined by Oil red $O$ staining as an index of macrovesicular lipid infiltration, was only raised in obese animals born to control fed mothers (Fig. 1b). In contrast, microvesicular steatosis was observed in the NRO group (Fig. 2). This was confirmed by the raised Kleiner scores for both steatosis (L: 0; O: 1; NRO: 3) and ballooning (L: 0; O: 0; NRO: 1) (but not inflammation) that is in accord with the TAG analysis (Brunt 2007).
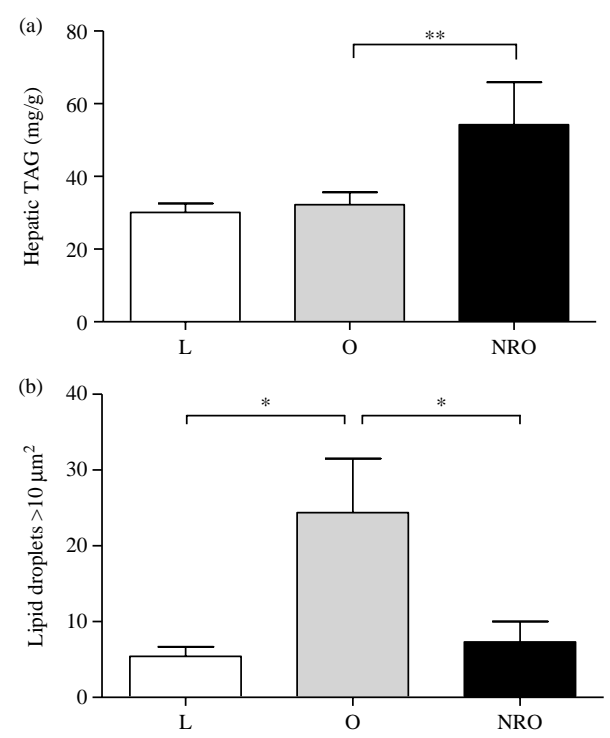

Figure 1 Effects of juvenile-onset obesity and early-to-mid gestational maternal nutrient restriction on hepatic (a) triglyceride content and (b) macrovesicular lipid infiltration as assessed by Oil red $\mathrm{O}$ staining. Values are expressed as means \pm S.E.M. for lean $(L, n=8)$, obese $(\mathrm{O}, n=8)$ and offspring born to nutrient-restricted mothers during early-mid gestation (NRO, $n=9$ ) at 1 year of age. Significant effects of juvenile-onset obesity (i.e. $L$ versus $\mathrm{O}$ ) and prenatal nutrient restriction $(\mathrm{O}$ versus NRO) were assessed using Student's unpaired t-test: ${ }^{*} P<0.01, * * P<0.005$. 
(a)

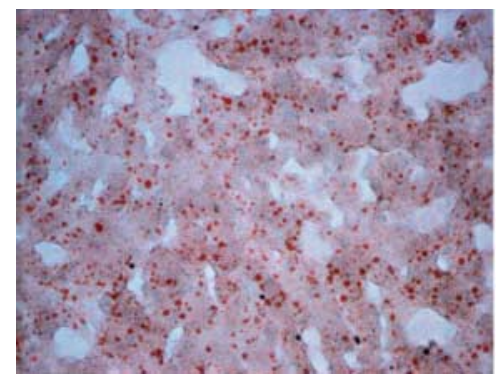

(b)

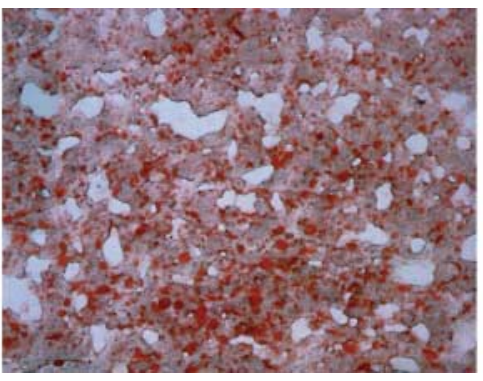

(c)

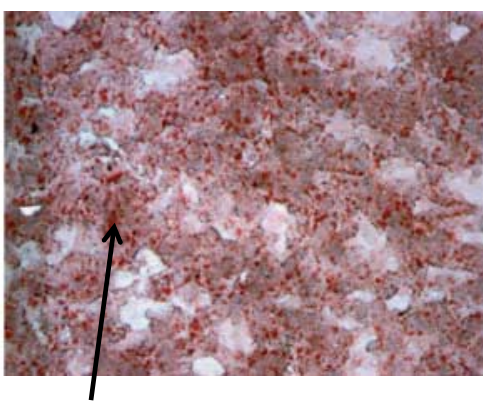

Figure 2 Effects of juvenile-onset obesity and early-to-mid gestational maternal nutrient restriction on hepatic macrovesicular lipid infiltration as assessed by Oil red O staining with typical examples of liver histology from each of the following groups (a) lean; (b) obese and (c) obese offspring born to nutrient-restricted (NR) mothers. Magnification is $\times 20$; note the macrovesicular lipid infiltration in the obese animals (b) compared with the microvesicular steatosis (as indicated by the arrow) as observed in the obese offspring born to nutrient-restricted mothers (c).

\section{Hepatic gene expression}

Following obesity, expression of genes that determine hepatic sensitivity to cortisol (i.e. the glucocorticoid receptor and $11 \beta$ hydroxysteroid dehydrogenase (HSD) type 2) and glucose (i.e. phosphoenolpyruvate carboxykinase (PCK2 (PEPCK)) and glucokinase IV) were all significantly increased while insulin-responsive genes including insulin receptor $(I R)$, IGF1 receptor $(I G F 1 R)$, IGF-binding protein 3 (IGFBP3), GH receptor $(G H R)$ and PPARA were all decreased irrespective of prenatal diet (Table 1).

Mitochondrial uncoupling protein 2 (UCP2) was also significantly increased in obese animals, a response that was unaffected by maternal diet during pregnancy. Maternal nutrient restriction followed by juvenile-onset obesity resulted in an upregulation of PPARG, its co-activator $(P G C 1 \alpha)$ and IGFBP1 in adult livers of 1 -year-old obese sheep. There was no effect of either prenatal diet or postnatal obesity on hepatic mRNA abundance for energy-sensing AMP-related kinase $(A M P K)$, insulin-sensitive adiponectin or inflammatory markers TNF and interleukin 6 (IL6; Table 1).

\section{Discussion}

We have shown that while exposure to a sedentary postweaning obesogenic environment alone has no effect on hepatic TAG content, when this is preceded by prenatal nutrient restriction coincident with early organogenesis of the fetal liver, this is significantly raised by early adulthood. These findings are in accord with adverse adaptations previously established within adipose tissue (Sharkey et al. 2009b) and the heart (Chan et al. 2009). In addition, hepatic TAG accumulation was accompanied with microvesicular steatosis that is indicative of advanced steatosis and, therefore, NAFLD (Reddy \& Sambasiva Rao 2006). Taken together, these findings

Table 1 Hepatic gene expression for lean $(\mathrm{L}, n=8)$, obese $(\mathrm{O}, n=8)$ animals and NR obese $(\mathrm{NRO}, n=9)$ at 1 year of age.

\begin{tabular}{|c|c|c|c|c|c|c|}
\hline Metabolic pathways & mRNA & $\mathbf{L}$ & $\mathbf{O}$ & NRO & $\begin{array}{l}\text { Juvenile-onset } \\
\text { obesity }\end{array}$ & $\begin{array}{l}\text { Prenatal } \\
\text { restriction }\end{array}$ \\
\hline \multirow[t]{2}{*}{ Glucose metabolism } & PCK2 & $1.0 \pm 0.1$ & $2.7 \pm 0.9$ & $4.4 \pm 1.1$ & $*$ & NS \\
\hline & Glucokinase IV & $1.0 \pm 0.4$ & $11 \pm 3.4$ & $30 \pm 8.4$ & $*$ & NS \\
\hline \multirow[t]{5}{*}{ Insulin sensitivity and growth } & Insulin receptor & $1.0 \pm 0.4$ & $0.3 \pm 0.06$ & $0.2 \pm 0.1$ & $*$ & NS \\
\hline & IGF1R & $1.0 \pm 0.2$ & $0.3 \pm 0.05$ & $0.6 \pm 0.1$ & $*$ & NS \\
\hline & IGFBP1 & $1.0 \pm 0.3$ & $1.1 \pm 0.2$ & $2.7 \pm 0.4$ & NS & $*$ \\
\hline & IGFBP3 & $1.0 \pm 0.2$ & $0.4 \pm 0.1$ & $0.4 \pm 0.1$ & $*$ & NS \\
\hline & $\mathrm{GH}$ receptor & $1.0 \pm 0.2$ & $0.4 \pm 0.1$ & $0.4 \pm 0.1$ & $*$ & NS \\
\hline \multirow[t]{5}{*}{ Glucocorticoids and inflammation } & $\begin{array}{l}\text { Glucocorticoid } \\
\text { receptor }\end{array}$ & $1.0 \pm 0.2$ & $3.8 \pm 1.1$ & $2.9 \pm 0.5$ & $t$ & NS \\
\hline & HSD11B1 & $1.0 \pm 0.1$ & $1.7 \pm 0.4$ & $4.7 \pm 1.1$ & NS & $*$ \\
\hline & HSD11B2 & $1.0 \pm 0.1$ & $2.0 \pm 0.2$ & $4.6 \pm 1.0$ & $*$ & $*$ \\
\hline & $T N F(\alpha)$ & $1.0 \pm 0.3$ & $1.0 \pm 0.4$ & $1.2 \pm 0.5$ & NS & NS \\
\hline & IL6 & $1.0 \pm 0.2$ & $0.5 \pm 0.1$ & $0.3 \pm 0.1$ & NS & NS \\
\hline \multirow{5}{*}{$\begin{array}{l}\text { Lipid metabolism and mitochondrial } \\
\text { bioactivity }\end{array}$} & PRKAA2 & $1.0 \pm 0.2$ & $2.2 \pm 0.8$ & $2.6 \pm 1.0$ & NS & NS \\
\hline & PPARA & $1.0 \pm 0.3$ & $0.2 \pm 0.05$ & $0.2 \pm 0.1$ & $*$ & NS \\
\hline & PPARG & $1.0 \pm 0.7$ & $2.2 \pm 0.6$ & $6.3 \pm 1.2$ & NS & + \\
\hline & $P G C 1 \alpha$ & $1.0 \pm 0.1$ & $0.4 \pm 0.03$ & $6.4 \pm 0.1$ & t & + \\
\hline & UCP2 & $1.0 \pm 0.1$ & $3.7 \pm 0.2$ & $3.9 \pm 0.3$ & $\neq$ & NS \\
\hline
\end{tabular}

Significant effects of juvenile-onset obesity (i.e $L$ versus $O$ ) and prenatal nutrient restriction (O versus NRO) were assessed using Student's unpaired $t$-test: ${ }^{*} P<0.05,{ }^{+} P<0.01,{ }^{\ddagger} P<0.005$. 
support the 'two hit' hypothesis and offer the possibility of using the sheep as a model for investigating the pathogenesis of NAFLD. The lack of NAFLD in those obese animals born to normally fed mothers is likely to reflect the much longer duration of exposure to an obesogenic challenge required to produce these symptoms in offspring that have not been nutritionally programmed (Bruce et al. 2009). Importantly, the hepatic TAG content of $3 \%$ in lean sheep is in accord with lean adult humans (Szczepaniak et al. 2005), as is the doubling in TAG accumulation with NAFLD (Kleiner etal. 2005). This is despite the fact that, in sheep, de novo synthesis of NEFA is restricted to adipose tissue, which is, therefore, the only source of long-chain TAG (Ingle et al. 1972).

\section{Obesity and hepatic mitochondrial function}

Our study confirms that, as in humans, PPARG gene expression is normally minimal in the liver and was only raised in those offspring born to nutrient-restricted mothers in which lipid accumulation was occurring, indicative of the onset of NAFLD (Medina-Gomez et al. 2007). Previously, the significance of this adaptation has been overlooked in small animal models of liver disease as it is not consistently observed, apparently being confined to those models showing leptin resistance, i.e. $o b / o b$ mice (Friedman et al. 1991). Upregulation of hepatic PPARG in obese offspring born to nutrientrestricted mothers could, therefore, be a consequence of raised TAG and/or an increase in IGFBP1 mRNA abundance, which would, if translated into protein, reduce hepatic bioavailablity of both IGF1 and 2 (Jones \& Clemmons 1995). One consequence of this would be a decrease in cell proliferation and/or apoptosis in steatotic hepatocytes (Kmiec 2001).

Obesity, alone, induced a reduction in $P G C 1 \alpha$, an expected response that is normally associated with hyperglycaemia (Medina-Gomez et al. 2007). PPARG and its co-activator PGC1 $\alpha$ induce the expression of genes involved in adipogenesis and have a prominent role in mitochondrial $\beta$ oxidation of NEFA (MedinaGomez et al. 2007). Upregulation of both of these genes in the livers from offspring born to nutrient-restricted mothers may represent a compensatory mechanism to the increased fat within the liver. Conversely, decreased mRNA abundance of both PGC1 $\alpha$ and PPARA in obese sheep suggests a decrease in hepatic NEFA oxidation but this was not accompanied by any lipotoxic effects. Mice deficient in PPARA show a minimal steatotic phenotype under fed conditions but manifest an exaggerated steatotic response to fasting (Lee \& Gonzalez 1996), indicating that defects in PPARA-inducible NEFA oxidation determine the severity of fatty liver phenotype in conditions reflecting energy-related stress. The severity of NAFLD would, therefore, be expected to progress faster with obesity in offspring born to nutrient-restricted mothers. Despite an increased abundance of UCP2 mRNA with obesity, indicative of increased reactive oxygen species production (Arsenijevic et al. 2000), PRKAA2 (AMPK) mRNA remained unchanged and, therefore, would not provide a protective effect against oxidative stress, which is consistent with some, but not all, animal (Chavin et al. 1999) and clinical (Ribeiro et al. 2004) studies.

\section{Obesity and hepatic glucose metabolism}

In this study, although obesity was accompanied with hyperinsulinaemia all animals were able to remain normoglycaemic. Plasma insulin was, however, raised further in offspring born to nutrient-restricted mothers, which reflects a resetting of insulin-glucose homeostasis (Sebert et al. 2009). This response may be mediated in part through compromised pancreatic development (Jones \& Ozanne 2009) in conjunction with a marked insulin resistance within the adipose tissue (Sharkey et al. 2009b). All obese sheep exhibited raised expression of glucose-sensitive genes including $G R$ (NR3C1), PCK2 and glucokinase IV. However, it is unclear whether this is due to increased cortisol sensitivity as HSD $11 B$ types 1 and 2 were both raised by the same amount and are likely to be mirrored by changes in activity (Whorwood et al. 2001). Therefore, it appears unlikely that hepatic sensitivity to cortisol was reset.

Adult obese sheep were able to maintain normoglycaemia despite increased transcription of gluconeogenic genes. The extent to which this adaptation is mediated by an increase in glycolysis, glycogen storage or increased uptake in glucose-sensitive tissues remains to be determined. However, increased glycogen storage seems unlikely due to the presence of raised plasma NEFA concentrations (Williams et al. 2007, Sebert et al. 2009), which would be predicted to decrease glucose conversion into glycogen for storage (Melania et al. 2004). Regardless of the prevailing plasma glucose concentration, lipid influx and de novo synthesis in NRO sheep exceeds hepatic lipid export and utilisation, thereby resulting in the storage of excess glucose as intrahepatic TAG. Increased glucokinase gene expression and TAG deposition in NRO animals were accompanied by the formation of microvesicular lipid droplets within the hepatocytes. This is an indication that macrovesicules have burst and is, therefore, a marker of the severity of NAFLD (Reddy \& Sambasiva Rao 2006) in these animals. In order to clarify this, further studies should investigate the effects on signalling molecules (Jump et al. 2005) that act by the transcription factors hepatocyte nuclear factor 4 (HNF4) and sterol regulatory element-binding protein-1c (SREBF1 (SREBP-1C)) to regulate hepatocyte differentiation and overall lipid metabolism (Jump et al. 2005, Hayhurst et al. 2008). Modification of both HNF4 and SREBF1 has been found associated with obesity-related diseases and may explain 
the link between insulin resistance and lipid-related alterations (Ueki et al. 2004). Their influence on NAFLD as yet to be uncovered but their unique ability to use NEFA as co-factors raises the question as to whether increase fat deposition in the liver promotes alteration upon the activity of the factors thus altering lipid metabolism.

A further finding of this study is that insulin-sensitive genes within the liver including $I R, G H R$ and $I G F 1 R$, IGFBP3, PPARA and PGC1 $\alpha$ were downregulated following juvenile-onset obesity despite the absence of TAG accumulation. Insulin resistance is an important mediator of hepatic TAG accumulation (Day 2002), promoting lipolysis in adipose tissue and influx of NEFA into the liver. The hyperinsulinaemia that accompanied obesity is, therefore, likely to have promoted de novo lipogenesis as well as indirectly inhibiting NEFA oxidation (Azzout-Marniche et al. 2000). This was potentially mediated by the decrease in both PPARA and $P G C 1 \alpha$ gene expression. The exacerbated insulin response, in conjunction with reduced expression of the $I R$, seen in obese offspring born to NR mothers is predicted to promote insulin resistance (Sanderson \& Smyrk 2005) and is likely to be an important contributory factor to the onset of NAFLD. Taken together, our findings suggest that, with time, these animals would become metabolically unstable, ultimately leading to hyperglycaemia, oxidative stress and the development of hepatic fibrosis.

\section{Obesity and hepatic inflammation}

Cytokines such as IL6 and TNF, produced by the liver, are established to play a role in the pathogenesis of NAFLD (Kmiec 2001, Jarrar et al. 2008), a process that has been suggested to be ameliorated by adiponectin (Kmiec 2001). In our sheep model, however, we did not observe an associated local hepatic inflammatory response as seen in more advanced clinical cases (Larter \& Farrell 2006, Tessari et al. 2009). The absence of inflammation is not unexpected, as adult clinical studies of NAFLD have also demonstrated a limited degree of hepatic inflammation (Brunt et al. 2009). We can now use this model to follow the more progressive disorders associated with NAFLD, which may be specific to fibrosis and the onset of non-alcoholic steatohepatitis (Larter \& Farrell 2006, Larter \& Yeh 2008). These studies could be combined with an assessment of the changes in cytokine receptor expression, which are likely to have an important role in the pathogenesis of NAFLD.

In conclusion, a combination of in utero nutrient restriction targeted during the period of early liver development is necessary to promote ectopic lipid accumulation within the liver following obesity. This developmental model of an early life nutritional intervention is confined to changes in the amount of feed consumed, rather than composition, now offers the potential to further understand developmental influences on fatty acid composition and liver enzymes with respect to fatty acid oxidation, lipid partitioning, fibrosis and on both the onset and severity of NAFLD.

\section{Materials and Methods \\ Experimental animals and tissue collection}

The experimental design of this study has been published previously (Williams et al. 2007, Chan et al. 2009, Sebert et al. 2009). Briefly, 25 twin-bearing sheep of a similar weight and body condition were randomly assigned to receive either a control ( 7-8 MJ/day of metabolisable energy, $n=16)$ or nutrient-restricted diet (50\% of control, $n=9$ ) from 30 to 80 days of gestation (term $147 \mathrm{~d}$ ) and were fed to requirements at all other times $(\sim 12-13 \mathrm{MJ} /$ day $)$. Offspring were delivered spontaneously and reared by their mothers as singletons (one twin was killed on day 7 ) until weaning (10 weeks) with no mothers producing twins of discordant body weight. There was no difference in growth rates between the groups either over the first week of life or subsequently up to the time of weaning. Then after weaning, control offspring were randomly assigned to either a lean $(\mathrm{L}$; field $(n=8))$ or an obesogenic $(\mathrm{O}$; group housed in a barn $50 \mathrm{~m}^{2}$, i.e. restricted activity $\left.(n=8)\right)$ environment with the ratio of male to females being 1:2. NR offspring were also exposed to an obesogenic environment (i.e. NRO). Obese and NRO offspring had access to hay and concentrate pellets (crude protein $140 \mathrm{~g} / \mathrm{kg}$, oil $3 \%, 12.7 \mathrm{MJ} / \mathrm{kg}$ dry matter; Manor Farm Feeds, Oakham, UK) ad libitum in a restricted physical activity environment to promote increased fat deposition and juvenileonset obesity. Obese offspring had $\sim 30 \%$ increase in food intake and $\sim 65 \%$ reduction in physical activity, as described previously (Williams et al. 2007). In contrast, lean animals remained at pasture and had unrestricted physical activity. Adult offspring were humanely killed by electrocortical stunning and exsanguination at 1 year of age to enable liver tissue sampling. After weighing, a representative liver sample from the right hepatic lobe was flash frozen in liquid nitrogen and stored at $-80^{\circ} \mathrm{C}$ until analysis was undertaken, in duplicate, for each animal. All procedures were performed in accordance with the UK Animals (Scientific Procedures) Act, 1986 and approved by the local ethics committee of the University of Nottingham.

\section{Molecular and biochemical analyses}

\section{Lipid extraction and TAG assay}

Lipids were extracted from frozen liver tissue $(\sim 400 \mathrm{mg})$ with a mixture of chloroform and methanol $(1: 1)$ and dissolved in tertbutyl alcohol/Triton X-100 mixture (1/1 by volume) before enzymatic measurement (Infinity Triglycerides Liquid Stable Reagent; Thermo Electron, Worthing, UK; Folch et al. 1957, Danno et al. 1992).

\section{Histological analyses}

Approximately, $1 \mathrm{~cm}^{3}$ blocks of frozen liver tissue were cut from the centre of the right hepatic lobe, embedded in 
optimum cutting temperature compound (OCT; Tissue-Tek; Miles, Naperville, IL, USA) and stored at $-80{ }^{\circ} \mathrm{C}$ until being processed. Frozen OCT liver tissue was cut into $10 \mu \mathrm{m}$ serial sections using a cryostat (Bright OTF model cryostat, specimen temperature set at $-21^{\circ} \mathrm{C}$ ). Three random liver sections per animal were fixed in $3.7 \%$ formaldehyde, stained with haematoxylin-eosin and imaged with a Leica DMRB microscope connected to Hamamatsu-Open Lab imaging system under $\times 20$ and $\times 40$ magnification lenses to assess liver architecture and density of voids resulting from lipid infiltration.

\section{Oil red $O$ staining for assessment of intracellular TAG content and assessment of severity of NAFLD}

Oil red $\mathrm{O}$ staining was used for quantitative determination of accumulated TAG in hepatocytes. Briefly, hepatic cryosections were fixed for $1 \mathrm{~h}$ in $3.7 \%$ formaldehyde, incubated in a $37 \%$ Oil red $\mathrm{O}$ solution for $30 \mathrm{~min}$ and washed with distilled water. Sections were counterstained with Harris's haematoxylin for $1 \mathrm{~min}$, washed with hydrochloric acid $(0.1 \%)$ for $30 \mathrm{~s}$, air dried and mounted with 10\% glycerol in Tris-buffered saline solution. The staining procedure was repeated for three separate sections per animal to obtain representative results. Once stained, sections were imaged as above and quantified by histomorphometry using Volocity software (Improvision, PerkinElmer, Coventry, UK). The slides were analysed three times at $\times 40$ magnification under a light microscope (Leica Microsystems, Milton Keynes, UK) for Oil red O staining. The average surface area of stained lipid droplets was calculated. Stained cryosections were further analysed for macro- and microvesicular steatosis. The extent of macrovesicular steatosis, ballooning and lobular inflammation was graded based on the Kliener scoring system (Kleiner et al. 2005). The intraand inter-assay coefficients of variances were $<5$ and $10 \%$ respectively. All histological analyses were undertaken while blinded to each intervention group.

\section{Total RNA isolation and RT}

Total RNA was extracted from $\sim 500 \mathrm{mg}$ of frozen liver tissue using Tri-Reagent (Sigma). Total RNA samples were treated for potential genomic DNA contamination with DNase 1 (Promega Ltd) and their A260/A280 ratio was assessed to confirm purity and concentration. cDNA was synthesised from $3 \mu \mathrm{g}$ RNA using 200 U Superscript II (Invitrogen Ltd) by RT in accordance with the manufacturer's protocol. Standard curves comprising a 1 in 10 dilution of primer-specific gel-purified amplicon: $1-10^{-8} \mathrm{ng} / \mu \mathrm{l}$ was used to ensure PCR amplification efficiency (1.95-2.0) as described previously (Chan et al. 2009); 185 rRNA was used as a housekeeping gene and was not found to be different between any of the study groups. All results were then calculated using the $2^{-\Delta C_{\mathrm{T}}}$ method (Livak \& Schmittgen 2001).

\section{Quantitative real-time PCR analyses}

The relative abundance of mRNA transcripts for each gene together with 185 was determined by quantitative PCR amplification, using a real-time thermocycler (Quantica,
Techne Incorporated, Barloword Scientific Ltd, Stone, UK), Quantitect SYBR green PCR kit (Qiagen Ltd), diluted RT reactions and 10-15 pmol of the forward and reverse primers as previously described (Chan et al. 2009). Primer sequences have been previously published (Bispham et al. 2005, Muhlhausler et al. 2007, Williams et al. 2007, Sebert et al. 2009) with the exception of GHR (F: AAG CCT GGA GGA AAC CAT ACG, R: TGC CAC TGC CAA GGT CAA C), IGF1 receptor (IGF1R) (F: TCT AAC TTT GTC TTT GCA AGA A, R: TCA CTG GCC CAG GAA ATG TC), glucokinase IV (F: GAC ATT GAC AAG GGC ATC CT, R: GTG GCC ACA GTG TCA TTC AC), IGFbinding protein 1 (IGFBP1) (F: GAT TAG CCA GGG AGC AGC AGA AG, R: CCG TCC AGC GAA GTC TCA CAC) and IGFBP3 (F: TCC AAG CAT GAG ACA GAA TAC GG, R: TTA TCC ACA CAC CAG CAG AAA CC). Real-time PCR conditions were $95^{\circ} \mathrm{C}$ (15 min); 35-40 cycles of $94{ }^{\circ} \mathrm{C}(45 \mathrm{~s}), 60{ }^{\circ} \mathrm{C}(30 \mathrm{~s}), 72{ }^{\circ} \mathrm{C}(45 \mathrm{~s})$; $72{ }^{\circ} \mathrm{C}(15 \mathrm{~min})$ for all primer sets. Gene expression data were normalised to the lean group (assigned as 1.0) and are, therefore, presented as a fold change.

\section{Statistical analysis}

Normality of data was assessed using the Kolmogorov-Smirnov test, using SPSS version 16.0 (SPSS, Inc., Chicago, IL, USA) and log transformed where necessary. Hepatic lipid content and gene expression data were first analysed by a univariate general linear model (GLM) procedure with the treatment group as a fixed factor. Owing to the unbalanced design of the study, offspring gender was added as a covariate. Selected a priori comparisons to test for the effects of prenatal nutrition ( $O$ versus $\mathrm{NRO}$ ) and postnatal obesity ( $\mathrm{L}$ versus $\mathrm{O}$ ) were performed using Student's unpaired $t$-tests. Data are expressed as mean values with their standard errors. For all comparisons, following Bonferroni correction, statistical significance was accepted when a probability of $5 \%$ was observed $(P<0.05)$.

\section{Declaration of interest}

The authors declare that there is no conflict of interest that could be perceived as prejudicing the impartiality of the research reported.

\section{Funding}

This work was supported by the Wellcome Trust Value in People Award (M A Hyatt), a British Heart Foundation Lectureship (D S Gardner, BS/03/01), the European Union Sixth Framework for Research and Technical Development of the European Community - The Early Nutrition Programming Project (FOOD-CT-2005-007036) and a Society for Endocrinology Small Programmes grant.

\section{References}

Arsenijevic D, Onuma H, Pecquer C, Raimbault S, Manning BS, Miroux B, Couplan E, Alves-Guerra M-C, Goubern M, Surwit R et al. 2000 Disruption of the uncoupling protein-2 gene in mice reveals a role in immunity and reactive oxygen species production. Nature Genetics 26 435-439. (doi:10.1038/82565) 
Ayala I, Castillo AM, Adanez G, Fernandez-Rufete A, Perez BG \& Castells MT 2009 Hyperlipidemic chicken as a model of non-alcoholic steatohepatitis. Experimental Biology and Medicine 234 10-16. (doi:10. 3181/0807-RM-219)

Azzout-Marniche D, Bacard D, Guichard C, Foretz M, Ferac P \& Foufelle F 2000 Insulin effects on sterol regulatory-element-binding protein-1c (SREBP-1C) transcriptional activity in rat hepatocytes. Biochemical Journal 350 389-393. (doi:10.1042/0264-6021:3500389)

Bellisari A 2008 Evolutionary origins of obesity. Obesity Reviews 9 165-180. (doi:10.1111/j.1467-789X.2007.00392.x)

Bispham J, Gardner DS, Gnanalingham MG, Stephenson T, Symonds ME \& Budge H 2005 Maternal nutritional programming of fetal adipose tissue development: differential effects on messenger ribonucleic acid abundance for uncoupling proteins and peroxisome proliferatoractivated and prolactin receptors. Endocrinology 146 3943-3949. (doi:10.1210/en.2005-0246)

Bruce KD, Cagampang FR, Argenton M, Zhang J, Ethirajan PL, Burdge GC, Bateman AC, Clough GF, Poston L, Hanson MA et al. 2009 Maternal high-fat feeding primes steatohepatitis in adult mice offspring, involving mitochondrial dysfunction and altered lipogenesis gene expression. Hepatology 50 1796-1808. (doi:10.1002/hep.23205)

Brunt EM 2007 Pathology of fatty liver disease. Modern Pathology 20 (Suppl 1) S40-S48. (doi:10.1038/modpathol.3800680)

Brunt EM, Kleiner DE, Wilson LA, Unalp A, Behling CE, Lavine JE \& Neuschwander-Tetri BA 2009 Portal chronic inflammation in nonalcoholic fatty liver disease (NAFLD): a histologic marker of advanced NAFLD-clinicopathologic correlations from the nonalcoholic steatohepatitis clinical research network. Hepatology 49 809-820. (doi:10.1002/ hep.22724)

Chan LL, Sebert SP, Hyatt MA, Stephenson T, Budge H, Symonds ME \& Gardner DS 2009 Effect of maternal nutrient restriction from early to mid gestation on cardiac function and metabolism after adolescent-onset obesity. American Journal of Physiology. Regulatory, Integrative and Comparative Physiology 296 R1455-R1463. (doi:10.1152/ajpregu. 91019.2008)

Chavin KD, Yang S, Lin HZ, Chatham J, Chacko VP, Hoek JB, WalajtysRode E, Rashid A, Chen CH, Huang CC et al. 1999 Obesity induces expression of uncoupling protein-2 in hepatocytes and promotes liver ATP depletion. Journal of Biological Chemistry 274 5692-5700. (doi:10. 1074/jbc.274.9.5692)

Danno H, Jincho Y, Budiyanto S, Furukawa Y \& Kimura S 1992 A simple enzymatic quantitative analysis of triglycerides in tissues. Journal of Nutritional Science and Vitaminology 38 517-521.

Day CP 2002 Pathogenesis of steatohepatitis. Best Practice \& Research. Clinical Gastroenterology 16 663-678. (doi:10.1053/bega.2002.0333)

Dixon JB, Bhathal PS \& O'Brien PE 2001 Nonalcoholic fatty liver disease: predictors of nonalcoholic steatohepatitis and liver fibrosis in the severely obese. Gastroenterology 121 91-100. (doi:10.1053/gast.2001. 25540)

Enriquez A, Leclercq I, Farrell GC \& Robertson G 1999 Altered expression of hepatic CYP2E1 and CYP4A in obese, diabetic ob/ob mice, and fa/fa Zucker rats. Biochemical and Biophysical Research Communications 255 300-306. (doi:10.1006/bbrc.1999.0202)

Fabbrini E, Mohammed BS, Magkos F, Korenblat KM, Patterson BW \& Klein S 2008 Alterations in adipose tissue and hepatic lipid kinetics in obese men and women with nonalcoholic fatty liver disease. Gastroenterology 134 424-431. (doi:10.1053/j.gastro.2007.11.038)

Fabbrini E, deHaseth D, Deivanayagam S, Mohammed BS, Vitola BE \& Klein S 2009 Alterations in fatty acid kinetics in obese adolescents with increased intrahepatic triglyceride content. Obesity 17 25-29. (doi:10. 1038/oby.2008.494)

Folch J, Lees M \& Sloane Stanley GH 1957 A simple method for the isolation and purification of total lipides from animal tissues. Journal of Biological Chemistry 226 497-509.

Friedman JM, Leibel RL, Siegel DS, Walsh J \& Bahary N 1991 Molecular mapping of the mouse ob mutation. Genomics 11 1054-1062. (doi:10. 1016/0888-7543(91)90032-A)

Fu J-F, Fang Y-L, Liang L, Wang C-L, Hong F \& Dong G-P 2009 The rabbit model of pediatric nonalcoholic steatohepatitis: the role of adiponectin. World Journal of Gastroenterology 15 912-918. (doi:10. 3748/wjg.15.912)
Hayhurst GP, Strick-Marchand H, Mulet C, Richard AF, Morosan S, Kremsdorf D \& Weiss MC 2008 Morphogenetic competence of HNF4 alpha-deficient mouse hepatic cells. Journal of Hepatology 49 384-395. (doi:10.1016/j.jhep.2008.04.024)

Hyatt MA, Budge H, Walker D, Stephenson T \& Symonds ME 2007 Ontogeny and nutritional programming of the hepatic growth hormoneinsulin-like growth factor-prolactin axis in the sheep. Endocrinology $\mathbf{1 4 8}$ 4754-4760. (doi:10.1210/en.2007-0303)

Ingle DL, Bauman DE \& Garrigus US 1972 Lipogenesis in the ruminant: in vivo site of fatty acid synthesis in sheep. Journal of Nutrition 102 617-623.

Jarrar MH, Baranova A, Collantes R, Ranard B, Stepanova M, Bennett C, Fang Y, Elariny H, Goodman Z, Chandhoke V et al. 2008 Adipokines and cytokines in non-alcoholic fatty liver disease. Alimentary Pharmacology \& Therapeutics 27 412-421. (doi:10.1111/j.1365-2036.2007.03586.x)

Jones JI \& Clemmons DR 1995 Insulin-like growth factors and their binding proteins: biological actions. Endocrine Reviews 16 3-34. (doi:10.1210/ edrv-16-1-3)

Jones RH \& Ozanne SE 2009 Fetal programming of glucose-insulin metabolism. Molecular and Cellular Endocrinology 297 4-9. (doi:10. 1016/j.mce.2008.06.020)

Jump DB, Botolin D, Wang Y, Xu J, Christian B \& Demeure O 2005 Fatty acid regulation of hepatic gene transcription. Journal of Nutrition 135 2503-2506.

Kleiner DE, Brunt EM, Van Natta M, Behling C, Contos MJ, Cummings OW, Ferrell LD, Liu YC, Torbenson MS, Unalp-Arida A et al. 2005 Design and validation of a histological scoring system for nonalcoholic fatty liver disease. Hepatology 41 1313-1321. (doi:10.1002/hep.20701)

Kmiec Z 2001 Cooperation of liver cells in health and disease. Advances in Anatomy, Embryology, and Cell Biology 161 1-151.

Larter CZ \& Farrell GC 2006 Insulin resistance, adiponectin, cytokines in $\mathrm{NASH}$ : which is the best target to treat? Journal of Hepatology $\mathbf{4 4}$ 253-261. (doi:10.1016/j.jhep.2005.11.030)

Larter CZ \& Yeh MM 2008 Animal models of NASH: getting both pathology and metabolic context right. Journal of Gastroenterology and Hepatology 23 1635-1648. (doi:10.1111/j.1440-1746.2008.05543.x)

Lee SS \& Gonzalez FJ 1996 Targeted disruption of the peroxisome proliferator-activated receptor alpha gene, PPAR alpha. Annals of the New York Academy of Sciences 804 524-529. (doi:10.1111/j.17496632.1996.tb18642.x)

Li ZZ, Berk M, McIntyre TM \& Feldstein AE 2009 Hepatic lipid partitioning and liver damage in nonalcoholic fatty liver disease: role of stearoyl-CoA desaturase. Journal of Biological Chemistry 284 5637-5644. (doi:10. 1074/jbc.M807616200)

Lidofsky SD 2008 Nonalcoholic fatty liver disease: diagnosis and relation to metabolic syndrome and approach to treatment. Current Diabetes Reports 8 25-30. (doi:10.1007/s11892-008-0006-1)

Lieber CS, Leo MA, Mak KM, Xu Y, Cao Q, Ren C, Ponomarenko A \& DeCarli LM 2004 Model of nonalcoholic steatohepatitis. American Journal of Clinical Nutrition 79 502-509.

Livak KJ \& Schmittgen TD 2001 Analysis of relative gene expression data using real-time quantitative PCR and the $2 \mathrm{~T}$ method. Methods 25 402-408. (doi:10.1006/meth.2001.1262)

Medina-Gomez G, Gray S \& Vidal-Puig A 2007 Adipogenesis and lipotoxicity: role of peroxisome proliferator-activated receptor gamma (PPARgamma) and PPARgamma coactivator-1 (PGC1). Public Health Nutrition 10 1132-1137. (doi:10.1017/S1368980007000614)

Melania M, Menotti C \& Geltrude M 2004 Effects of dietary fatty acids on insulin sensitivity and secretion. Diabetes, Obesity \& Metabolism 6 402-413. (doi:10.1111/j.1462-8902.2004.00356.x)

Moscatiello S, Manini R \& Marchesini G 2007 Diabetes and liver disease: an ominous association. Nutrition, Metabolism, and Cardiovascular Diseases 17 63-70. (doi:10.1016/j.numecd.2006.08.004)

Muhlhausler BS, Duffield JA \& McMillen IC 2007 Increased maternal nutrition stimulates peroxisome proliferator activated receptor-gamma, adiponectin, and leptin messenger ribonucleic acid expression in adipose tissue before birth. Endocrinology 148 878-885. (doi:10.1210/ en.2006-1115)

Reddy JK \& Sambasiva Rao M 2006 Lipid metabolism and liver inflammation. II. Fatty liver disease and fatty acid oxidation. American Journal of Physiology. Gastrointestinal and Liver Physiology 290 G852-G858. (doi:10.1152/ajpgi.00521.2005) 
Ribeiro PS, Cortez-Pinto H, Sola S, Castro RE, Ramalho RM, Baptista A, Moura MC, Camilo ME \& Rodrigues CM 2004 Hepatocyte apoptosis, expression of death receptors, and activation of NF-kappaB in the liver of nonalcoholic and alcoholic steatohepatitis patients. American Journal of Gastroenterology 99 1708-1717. (doi:10.1111/j.1572-0241. 2004.40009.x)

Sanderson SO \& Smyrk TC 2005 The use of protein tyrosine phosphatase 1B and insulin receptor immunostains to differentiate nonalcoholic from alcoholic steatohepatitis in liver biopsy specimens. American Journal of Clinical Pathology 123 503-509. (doi:10.1309/ 1PX2LMPQUH1EE12U)

Sebert SP, Hyatt MA, Chan LL, Patel N, Bell RC, Keisler D, Stephenson T, Budge H, Symonds ME \& Gardner DS 2009 Maternal nutrient restriction between early-to-mid gestation and its impact upon appetite regulation following juvenile obesity. Endocrinology 150 634-641. (doi:10.1210/ en.2008-0542)

Sharkey D, Fainberg HP, Wilson V, Harvey E, Gardner DS, Symonds ME \& Budge H 2009a Impact of early onset obesity and hypertension on the unfolded protein response in renal tissues of juvenile sheep. Hypertension 53 925-931. (doi:10.1161/HYPERTENSIONAHA.108. 122812)

Sharkey D, Gardner DS, Fainberg HP, Sebert S, Bos P, Wilson V, Bell R, Symonds ME \& Budge H 2009b Maternal nutrient restriction during pregnancy differentially alters the unfolded protein response in adipose and renal tissue of obese juvenile offspring. FASEB Journal 23 1314-1324. (doi:10.1096/fj.08-114330)

Sharkey D, Symonds ME \& Budge H 2009C Adipose tissue inflammation: developmental ontogeny and consequences of gestational nutrient restriction in offspring. Endocrinology 150 3913-3920. (doi:10.1210/ en.2008-1784)

Szczepaniak LS, Nurenberg P, Leonard D, Browning JD, Reingold JS, Grundy S, Hobbs HH \& Dobbins RL 2005 Magnetic resonance spectroscopy to measure hepatic triglyceride content: prevalance of hepatic steatosis in the general population. American Journal of Physiology. Endocrinology and Metabolism 288 E462-E468. (doi:10. 1152/ajpendo.00064.2004)

Tessari P, Coracina A, Cosma A \& Tiengo A 2009 Hepatic lipid metabolism and non-alcoholic fatty liver disease. Nutrition, Metabolism, and Cardiovascular Diseases 19 291-302. (doi:10.1016/j.numecd.2008.12.015)

Ueki K, Kondo T, Tseng YH \& Kahn CR 2004 Central role of suppressors of cytokine signaling proteins in hepatic steatosis, insulin resistance, and the metabolic syndrome in the mouse. PNAS 101 10422-10427. (doi:10.1073/pnas.0402511101)

Weltman MD, Farrell GC \& Liddle C 1996 Increased hepatocyte CYP2E1 expression in a rat nutritional model of hepatic steatosis with inflammation. Gastroenterology 111 1645-1653. (doi:10.1016/S00165085(96)70028-8)

Whorwood CB, Firth KM, Budge H \& Symonds ME 2001 Maternal undernutrition during early to midgestation programs tissue-specific alterations in the expression of the glucocorticoid receptor, 11 betahydroxysteroid dehydrogenase isoforms, and type 1 angiotensin II receptor in neonatal sheep. Endocrinology 142 2854-2864. (doi:10. 1210/en.142.7.2854)

Williams PJ, Kurlak LO, Perkins AC, Budge H, Stephenson T, Keisler D, Symonds ME \& Gardner DS 2007 Hypertension and impaired renal function accompany juvenile obesity: the effect of prenatal diet. Kidney International 72 279-289. (doi:10.1038/sj.ki.5002276)

Xu A, Wang Y, Keshaw H, Xu LY, Lam KS \& Cooper GJ 2003 The fat-derived hormone adiponectin alleviates alcoholic and nonalcoholic fatty liver diseases in mice. Journal of Clinical Investigation 112 91-100. (doi:10. 1172/JCI17797)

Received 30 July 2010

First decision 22 September 2010

Accepted 1 November 2010 